\title{
Quantitative analysis of free mica in sand and hardened concrete blocks by SEM-EDS
}

\author{
LEONA O CONNOR ${ }^{* 1} \&$ ROBBIE GOODHUE ${ }^{2}$
}

1iCRAG, Trinity College Dublin, Ireland. mulveyle@tcd.ie ${ }^{2}$ iCRAG, Trinity College Dublin, Dublin 2, Ireland. goodhuer@tcd.ie

The presence of muscovite mica in abundant quantities in the aggregate of concrete blocks has been reported as a factor in their deterioration. The lack of viable quantitative analytical methods to determine the $<63 \mu \mathrm{m}$ free mica concentration in sand and in the cement matrix of hardened concrete blocks is a well known industrial concern.

Demonstrated here is the development and results of a viable quantitative method using SEM-EDS on sand samples from suppliers and on concrete from houses exhibiting the damage attributed to free mica. This analysis was carried out using a Tescan MIRA3 field emission SEM coupled with two Oxford X-Max $150 \mathrm{~mm}^{2}$ detectors with the raw data processed using Oxford Instruments Aztec Feature software.

This method will allow further research into failures due to excessive free mica, assist decisions regarding remediation, and contribute to National standards that will minimise future failures.
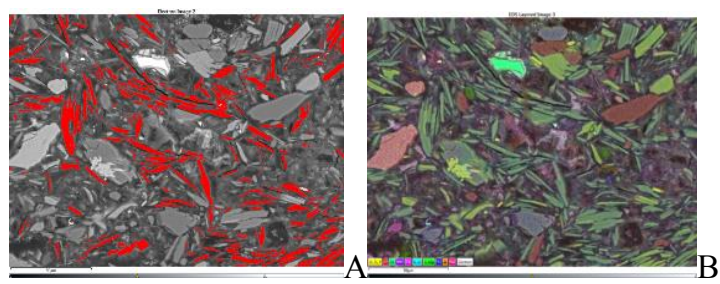

Figure 1: (A) Back scattered electron SEM image of the cement paste of a hardened concrete block at $1200 \mathrm{x}$ magnification with free mica identified in red by morphology. (B) Corresponding layered EDS element map with free mica identified by potassium in green. 